\title{
Role of breast crawl in maternal health and wellbeing
}

\author{
Tiwari $V^{1}$, Singh $N^{2}$, Purohit ${ }^{3}$, Shyam $S^{4}$ \\ ${ }^{1}$ Dr Varsha Tiwari, Assistant Professor, Department of Pediatrics, ${ }^{2}$ Dr. Neelam Singh, Assistant Professor, Deparment of \\ Obstetrics \& Gynaecology. ${ }^{3}$ Dr Ashish Purohit, Assistant Professor, Department of Medicine, ${ }^{4}$ Dr Saroj Shyam, Senior \\ Resident, Department ofobstetrics \& Gynaecology. All are affiliated with LN Medical College, Bhopal (MP) India.
}

Address for Correspondence: Dr VarshaTiwari, Email: dr.varshatiwari021@gmail.com

\begin{abstract}
Background: Initiation of breast-feeding within hour of birth is very crucial. Except human other mammalian species start immediate breast feeding of their newborn. Human delays the breast feeding from hours to days. it is also known that even human babies can start breast feeding on their own like the young ones of the animals. Every newborn, when placed on her mother's abdomen, soon after birth, he has the capability to find her mother's breast all on his own \& to decide when to take the first breast feed this is known as breast crawl. These advantages not only protect mothers health in several ways, also benefits whole family, emotionally and economically. Methods: A prospective cohort observation study done on 200 research cases \& similarly control cases were selected from full term newborn babies delivered vaginally, in Dr. B.R. Ambedkar Memorial, Hospital and Pt JNM medical college Raipur (C.G.). Results: Out of 200 full term babies, 166 babies able to successfully crawl within in 50 min. Out of 166 breast crawl mothers-(1) 95\% mothers had early expulsion of placenta. (2) $96 \%$ mothers had decrease in uterine size. (3) $100 \%$ breast crawl mothers were satisfied. (4) $93 \%$ mother had no anemia in post partum period of same pregnancy. Conclusions: This is new research study in India so far. Breast crawl has beneficial effect on health of mother by preventing postpartum hemorrhages, anemia, breast feeding failure \& sense of wellbeing.
\end{abstract}

Key words: Breast crawl, Breast feeding, maternal health.

\section{Introduction}

Every newborn, when placed on her mother's abdomen, soon after birth, has the ability to find her mother's breast all on her own and to decide when to take the first breastfeed. This is called the 'Breast Crawl'. It was first described in 1987 at the Karolinska Institute in Sweden [1]. The description of the Breast Crawl, compiled from the article, is as follows:

Immediately after birth the child was dried and laid on the mother's chest. In the control group a regular behavioral sequence, previously not described in the literature, was observed. After 15 minutes of comparative inactivity, spontaneous sucking and rooting movements occurred, reaching maximal intensity at 45 minutes. The first hand-to-mouth movement was observed at a mean of $34 \pm 2$ minutes after birth and at 55+ minutes the infant spontaneously found the nipple and started to suckle.

Manuscript received: $7^{\text {th }}$ May 2015

Reviewed: $15^{\text {th }}$ May 2015

Author Corrected: $4^{\text {th }}$ June 2015

Accepted for Publication: $16^{\text {th }}$ June 2015
These findings suggest that an organized feeding behaviour develops in a predictable way during the first hours of life, initially expressed only as spontaneous sucking and rooting movements, soon followed by hand-to-mouth activity together with more intense sucking and rooting activity, and culminating in sucking of the breast.'

"Breast crawl helps uterine contraction and faster expulsion of the placenta, reduces maternal blood loss and prevents anaemia[2]. Prolactin (PRL) and oxytocin (OT) play the main roles in milk production and secretion in puerperal women. Prolactin is essential for the initiation and maintenance of lactation. Prolactin secretion in breast feeding women is maintained physiologically by suckling and there is much evidence from in vivo studies that suckling per se is the most powerful natural stimulus for Prolactin release [3-5].

Suckling also stimulates Oxytocin release from the posterior pituitary [6,7], the Oxytocin being released in a pulsatile manner during suckling [8,9]. Puerperal 
women with hypogalactia or problems related to the breast and nipples, such as stagnation mastitis and retracted nipples, generally receive manual breast massage. So, suckling and breast massage may be common breast stimulants for puerperal women, thus Breast feeding accelerates the process of involution of uterus, reduces the chances of post partum hemorrhages and thus prevent anemia in mothers.

The postpartum period brings physiological and psychological transitions that predispose a large number of women to depressive symptoms. Breast crawl helps in preventing depressive episodes and satisfies mothers. In this study we are trying to find effect of breast crawl immediately after birth l(like the young ones of animal) in maternal health and wellbeing.

\section{Material and Methods}

Settings- Department of Pediatrics \& Neonatology and Department of Obstetrics and Gynecology, Pt JNM Medical College and Dr B RAmbedkarMemorial Hospital Raipur, C.G, India

Study Design- A prospective cohort observational study on 200 babies born in Dr BR Ambedkar Memorial Hospital Raipur CG.

\section{Selection of Cases- Inclusion criteria-}

1. Gestational age more than 36 weeks,

2. Apgar score above 6,

3. Weight above $1800 \mathrm{gm}$.

4. Normal and healthy, born by normal vaginal deliveries in labour room of dept of obstetrics and gynecology medical college raipur were selected.

\section{Exclusion criteria-}

1. Those babies born of outborn and inborn LSCS,

2. Apgar score $<6$,

3. Weight $<1800 \mathrm{gm}$

4. Congenital anomalies

Hemoglobin of mothers measured before delivery and after 15 days follow up using sahil'shemoglobinometer. Uterine sizes were measured above pubic symphysis using measuring tape.

To study the expulsion of placenta we had taken 3- 5 minutes time after delivery of baby and seen the whole placenta i.e. both maternal and fetal surface with all the cotyledons and umbilical cord were expelled.( Fundal height was measured above pubic symphysis following delivery, the fundus lies about $13.5 \mathrm{~cm}\left(5{ }^{\prime 2}\right.$ ') above the pubic symphysis during the first $24 \mathrm{hrs}$, the level remains constant thereafter there is steady decrease in height by $1.25 \mathrm{~cm}$ in next $24 \mathrm{hrs}$, so that by the end of second weeks(12-14 days) the uterus becomes the pelvic organ.)

\section{Summary of the procedure}

Procedure for Breast Crawl for optimum results

1) Discuss it with the mother during antenatal visits

2) Orient the staff to the technique

3) Avoid labour analgesia as far as possible

Just after delivery, If the baby has cried well, immediately after birth and is stable she/he does not need oro-nasal suction then dry the baby nicely except for the hands. Raise the mother's head on the pillow so that the mother can see her baby easily during the Breast Crawl. Show the baby to the mother with a cheek to cheek contact. Now keep the naked baby on the mothers abdomen with the head in between the bare, unwashed and unwiped breast. Cover the baby and mother together with a cloth, to keep warm, while skin to skin contact continues, mothers hand can support the baby's back. This will help in maintaining the baby's position, avoid slipping of the baby and give the added advantage of maternal touch. Continue in this position till the baby takes the first breast feed; which mostly will achieve by 30-60 minutes. In case the baby's several attempts to latch on the the breast fail, then the baby can be gently moved nearer to the breast and assisted by a helper to attach to the breast. The mother should not be moved out of the labour room till the first breast feed is completed. A female relative or even the father can be called in at the earliest and acceptable time to be a part of this important magical emotional interaction. Breast odour is strong stimulus which drives the baby towards nipple. The babies sense of smell is well developed. The odour of a substance secreted by nipple is similar to the smell of a substance in amniotic fluid which surrounds the baby womb. Nipple massage by the baby makes it protract. This helps in attachment. Nipple massage also releases hormone called oxytocin in mother, this helps to contract the uterus, prevent the bleeding and reduce the maternal anemia. Babies hand should have amniotic fluid on them, as it guides baby to nipple .Even with its limited vision baby can see areola. If baby raises its head it can also see her mothers face also. Then it reaches nipple, raises her head and gets nicely attached 
on to the nipple with her mouth widely open to take a mouthful of breast.This first skin to skin contact must continue until the baby finishes the first breast feed. This is the first feed to the babies that gives moment of joy for mother and baby over a ten minutes and create higher human potential of successful growth and development, cuddle, love, security and mother baby bonding.

\section{Results}

It was observed that out of 200 babies, 166 were able to reach the breast of mother by crawling with in $30-50$ minutesof time.

Table No.1: Distribution of patients and placental expulsion

\begin{tabular}{|c|c|c|c|c|c|}
\hline & \multirow{2}{*}{$\begin{array}{l}\text { Total } \\
200\end{array}$} & \multicolumn{2}{|c|}{ Early expulsion of placenta(2-4 minute) } & \multicolumn{2}{|c|}{ Late expulsion of placenta $(>5$ minute $)$} \\
\hline & & No. & $\%$ & No. & $\%$ \\
\hline $\begin{array}{l}\text { Breast } \\
\text { crawl }\end{array}$ & 166 & 158 & 95 & 8 & 5 \\
\hline $\begin{array}{l}\text { Non Breast } \\
\text { crawl }\end{array}$ & 34 & 10 & 19 & 24 & 71 \\
\hline
\end{tabular}

In this study it was found that early expulsion of placenta occurred in 95\% of breast crawl mothers than (19\%) in Non breast crawl mothers. While late expulsion found in 5\% Breast Crawl and 71\% in Non breast crawl mothers which was found to be statistically significant with $\mathrm{p}$ value $<0.05$.

Table No. 2: Decrease in uterine size after 2 weeks follow up

\begin{tabular}{|l|l|l|l|l|l|}
\hline & Total & $<6$ cm abovep.s & \multicolumn{2}{l|}{ *6cm above p.s } \\
\cline { 3 - 6 } & $\mathbf{2 0 0}$ & No. & \% & No. & \% \\
\hline Breast crawl & 166 & 160 & 96 & 6 & 4 \\
\hline $\begin{array}{l}\text { Non breast } \\
\text { crawl }\end{array}$ & 34 & 30 & 88 & 4 & 12 \\
\hline
\end{tabular}

*(Where P.S is pubic symphysis)

It was found that there were 160 breast crawl mothers had decrease in uterine size measured $<6 \mathrm{~cm}$ above P.S while 30 non breast crawl mothers had decrease in uterine size $<6 \mathrm{~cm}$ above P.S. On the other hand 6 breast crawl mothers had palpable uterus $>6 \mathrm{~cm}$ above P.S and the no. was 4 out of 34 in Non breast crawl mothers. Student t test was applied in two groups and the result was found to be statistically significant. $(\mathrm{p}<0.05)$.

Table No 3: Assessment of well being of mothers

\begin{tabular}{|l|l|l|l|l|l|}
\hline & \multirow{2}{*}{ Total } & Satisfied & No. & \% & Unsatisfied \\
\hline Breast crawl & 166 & 166 & 100 & No. & \% \\
\hline $\begin{array}{l}\text { Non Breast } \\
\text { crawl }\end{array}$ & 34 & 30 & 88 & 4 & - \\
\hline
\end{tabular}

It was found that, there were all breast crawl mothers satisfied by means of wellbeing while among non breast crawl mothers 30 were satisfied and 4 were not satisfied.(p value 0.1 ,thus the result was not significant.) 
Table No 4: Anemia in mothers

\begin{tabular}{|l|l|l|l|l|}
\hline & Hb gm\% >11gm/dl & Hb gm\% <11gm/dl \\
\cline { 2 - 5 } & No. & \% & No. & \% \\
\hline Breast crawl & 156 & 93 & 10 & 7 \\
\hline Non breast crawl & 10 & 29 & 24 & 71 \\
\hline
\end{tabular}

In this study it was found that Breast crawl mothers had decreased blood loss and thus less anemia during post partum period i.e $93 \%$ had hemoglobin $>11 \mathrm{gm} / \mathrm{dl}$ than non-Breast crawl mothers, in which $29 \%$ had hemoglobin $>11 \mathrm{gm} / \mathrm{dl}$ while $71 \%$ had hemoglobin $<11 \mathrm{gm} / \mathrm{dl}$. Student unpaired t-test in both groups were applied and results were significant with $\mathrm{p}$ value $<0.05$.

\section{Discussion}

In present study out of 200 babies mothers, 166 were successfully achieved breast crawl. Widstrom et al 1987 conducted study in 21 newborn showing that 20 (95\%) newborn successfully achieved breast crawl [1]. Righard and Alade et al 1990 studied the hindering factors for initiation of breast crawl. They divided 78 newborn into contact group and separation group infant was placed on mother's abdomen immediately after the birth but removed after $20 \mathrm{~min}$ for measuring and wrapping which took another $20 \mathrm{~min}$ and after which infant was returned to mother). Among both groups pethedine was given to some mothers. Among the contact group of $38(48.7 \%)$ newborn early sucking pattern is observed in $20(52.6 \%)$ of newborn. While in separation group of $34(51.3 \%)$ only $15(44.1 \%)$ of newborn were able to have normal breast crawl. Similarly $31(39.7 \%$ ) newborn of mothers who did not received pethedin were successfully able to do breast crawl in comparison with that of the 15 (19.2\%) newborn of mothers who received pethidine during labour [11].

Author recommended that naked infant should be left undisturbed on mothers abdomen until the breast feed is completed and infants effort to take breast crawl activity should be encouraged. Use of drugs given to mother during labour should be restricted.

widstrometal1987, Richard et.al.1990 Founds that earliest the newborn baby kept with naked body contact with mother, more the ability to adapt, coordinate, orientation \&attachment develops[1,11].

Again Widstrom et al1990 studied that breast crawl facilitate bonding. If the lips of infant touch the mother's nipple in the first hour life, a mother will decide to keep her baby $100 \mathrm{~min}$ [12].
Righard and Alade et al studied that breast crawl help in improvement of immediate and long term breast feeding success. Early sucking pattern is of prognostic value for duration and success of breast feeding [11]. Christensson et al 1992 studied that breast crawl helps in maintain temperature, facilitate in maintaining blood sugar level and maintain in acid base balance[13]. Varendi et al 1994 studied that among 30 newborn 25 $(83.3 \%)$ of babies were able to complete breast crawl successfully. This study also indicated that babies preferred their mothers unwashed breast than that of washed breast as nipples and areola are dense in glands which are responsible for odour[14].Conclusion olfactory is most studied input for breast crawl and is believed to be most important. Unnecessary routine cleaning of breast may interfere with establishment of successful early breast feeding by elimination of infants access to biologically relevant chemical agents present in the odour of the breast. Excessive use of product that eliminates or mask the natural odour signals like deo/perfumes should be avoided.

Christensson et al 1995 studied that breast crawl results in less crying. Study compared crying between babies kept in breast crawl position with those kept in bed next to mother during the first $90 \mathrm{~min}$ after birth. Infant in the bed cried for a significantly longer time than the babies in breast crawl position. Study shown that babies kept in skin to skin contact cried for $60 \mathrm{sec}$ in first 2530 min in comparison with those kept in cot who cried for $1094 \mathrm{sec}$. On the basis of this observation author concluded that infant in cotcried for significantly longer time than babies in skin to skin contact [15].

Varendi et al1996 again studied that within $1^{\text {st }}$ hour of birth significantly more number of babies $70 \%$ spontaneously selected a breast treated with amniotic fluid than the alternative untreated breast [16].This 
attraction appears to be based on olfactory clue. Conclusion -olfactory response not only guide a neonates a overt behavior response but also appears to having calming effect on infant and provide basis for early individual recognizing mother. Righard \& alade studied earlier hours of naked body contact between mother \&newborn ability to latch well \& effectively remove milk from breast \& suggests that maternal breastfeeding satisfaction scores may predict maturity of mothers milk at 6 weeks makes sense physiologically [11].

Winsbergand porter et al 1998 studied that breast odour from mother exert a pheromone like effect on the newborns first to locate the nipple[17].

Klaus and Kennelet al reviewed many of these studies and gave a beautiful description of breast crawl [18].Credit of using word breast crawl as 'noun' should be given to Klaus. Breast crawl is associated with variety of sensory, central, motor and neuroendocrine component all directly or indirectly helping the baby to move and facilitate her survival in new work. Babies use taste and smell of amniotic fluid on its hand to make a connection with a lipid substance on nipple related to amniotic fluid.(Klaus kennel 2001)

- Breast crawl help in expulsion of placenta and reduce uterine bleeding.

- Stepping reflex helps the newborn to push against her mother's abdomen to propel her toward the breast.

- Pressure from the infant's feet on the abdomen may help on the in expulsion of placenta and decrease uterine bleed.

- horizontal motion is achieved by using small pushups and lowering one arm first in the direction they wish to go. The ability to move its hand in reacting motion enables the babies to claim the nipple. This help to stimulat, elongate and protract the nipple and facilitate attachement- this leads to oxytocin surge from mother's pituitary gland to her blood stream. (Klaus kennel 2001) oxytocin acting on a multiple oxytocin receptor in brain plays following role.

a) Stimulation of vagal motor nucleus releasing 19 different gastrointestinal hormones including insulin, cholecystikinin and gastrin. Five of these nineteen hormonesstimulate baby's and mother'svilli and increase the surface area and absorption of calories with each feeding

b) Important for initiation of maternal behavior and for facilitation of bonding between the mother and baby.

c) In mother it results in slight sleepiness, euphoria and increased pain thresholdand feeling of increased love for infant. It appears that during breast feeding, elevated level of oxytocin is associated with increased brain level.

Matthiesenet al demonstrated that hormones to increase milk supply are increased when mothers hold their naked newborn against their bare chest \&breast feed [18].Coulsoen et al observed holding baby with clothes in postnatal area is termed as Biological nurturing \&also known to benefit breast feeding[20]. Esibolboro Mezzacappa assessed effect of breast feeding on maternal health shows that cessation of breast feeding was associated with worse mood, more stress \& greater number of physiological symptom to mother[21]. Punthmatharith \& singh,2005 found maternal satisfaction with infant breastfeeding within1hour after birth[22].

Ruth cantriletal again at el found that sustained naked body contact with attention to newborn instinctive feeding behaviours may improve breastfeeding outcomes for women \& boost their breastfeeding confidence at $2 \mathrm{wks}$ postpartum [23].

\section{Conclusion}

Breast crawl accelerates the process of involution of uterus, reducing the chances of post partum hemorrhage and anemia. It also adds sense of wellbeing in mother thus prevent post partum depression. Breast crawl helps in early initiation of feeding which is extremely important for establishing successful lactation which in turns helps the parents for spacing their children thus promotes family planning.

\section{Funding: Nil \\ Conflict of interest: Nil \\ Permission from Institutional Research Board (IRB): Yes}

\section{References}

1.Widstrom AM, Ransjo-Arvidson AB, ChristenssonNK, Matthiesen AS, Winberg J, UvnasMoberg K.Gastric suction in healthy newborn infants: Effects on circulation and developing feeding behaviour.Acta Paediatr Scand. 1987 Jul;76(4):566-72. 
2. Breast crawl' phenomenon benefits mothers and newborns. http://www.unicef.org/ cited on march 2015

3.Noel CL, Suh HK, Erantz AG. Prolactin release during nursing and breast stimulation in postpartum and nonpostpartumsubjects . J Clin Endocrinol Metab. 1974 Mar;38(3):413-23.

4.Leong DA, Frawley SL, and Neill JD. Neuroendocrine control of prolactin secretion.Annu Rev Physiol. 1983;45:109-27.

5. Martini L, Ganong WF, eds. Frontiers in neuroendocrinology.New York: Raven Press, 1980; 129-155.Available fromwww.researchgate.net/

6.Weitzman RE, Leake RD, Rubin RT, Fisher DA. The effect of nursing on neurohypophyseal hormone and prolactin secretion in human subjects.J Clin Endocrinol Metab.1980 Oct;51(4):836-9.

7.Dawood MY, Khan-Dawood FS, Wahi RS, Fuchs F. Oxytocin release and plasma anterior pituitary and gonadal hormones in women during lactation. J Clin Endocrinol Metab. 1981 Apr;52(4):678-83.

8. Cobo E, Bernal MH, de Gaitan E, Quintero CA. Neurohypophyseal hormone release in the human. Am J Obstet Gynecol. 1967 Feb 15;97(4):519-29.

9.McNeilly AS, Robinson ICAF, Houston MJ, Howie $\mathrm{PW}$. Release of oxytocin and prolactin in response to suckling.Br Med J (Clin Res Ed). 1983 Jan 22;286(6361):257-9.

10. Lauwers J, Woessner C. Counseling the nursing mother: a reference handbook for health care providers and lay counselors. Wayne NJ: CEA of Greater Philadelphia Avery Publishing Group Inc., 1983. Available fromhttps://books.google.co.in

11. Righard L, Alade MO Effect of delivery room routines on success of first breastfeed.Lancet. 1990 Nov 3;336(8723):1105-7.

12. Widstrom AM, Wahlberg V, Matthiesen AS. Shortterm effects of early suckling and touch of the nipple on maternal behaviour.Early Hum Dev. 1990 Mar;21(3):153-63.
13. Christensson K, Sileses C, Moreno L, Belaustequi A, De La Fuente P, Lagercrantz H. Temperature, metabolic adaptation and crying in healthy newborns cared for skin -to-skin, or in cot. ActaPaediatrica, Scandinavica, 1992; 8: 488-503. Available fromhttp://www.ncbi.nlm.nih.gov/

14. Varendi H, Porter RH, Winberg J Does the newborn baby find the nipple by smell? Lancet. 1994 Oct 8;344(8928):989-90.

15. Christensson K, Cabera T, Christensson E, UvnasMoberg K, Winberg J. Separation distress call in the human neonate in the absence of maternal baby contact. ActaPaediatrica, 1995; 84: 1174-6. Available fromhttp://www.ncbi.nlm.nih.gov/

16.Varendi H, Porter RH, Winberg J Attractiveness of amniotic fluid odour: Evidence of prenataloffactorylearing? Acta Paediatr. 1996 Oct;85(10):1223-7.

17. Winberg J, porter RH. olfaction and human neonatal behavior: clinical implications. Acta Paediatr. 1998 Jan;87(1):6-10.

18.Klaus MH, Kennell JH, Plumb N, Zuehlke S.Pediatrics. Human maternal behavior at the first contact with her young.1970 Aug;46(2):187-92

19. Matthiesen AS, Ransjo-Arvidson AB, Nissen E, Uvnas-Moberg K. Postopartum maternal oxytocin release by newborns : Effects of infant hand massage and sucking. Birth, 2001; 29: 13-19.

20. Colson, S. D., Meek, J., \& Hawdon, J. M. (2008). Optimal positions for the release of primitive neonatal reflexes stimulating breastfeeding. Early Human

Development, 84(7), 441-449.

www.biologicalnurturing.com

21E. Sibolboro Mezzacappa .A preliminary study of the effects of breast-feeding on maternal health.International Journal of Behavioral Medicine September 1997, Volume 4, Issue 3, pp 230-241. http://link.springer.com/

22.Punathamarith \& sing, 2005.A pshycometric assessment of $\mathrm{H} \& \mathrm{H}$ lactation scale in a thai mothers using a repeated measurement design. Nursing research,54(5),313-323 
23. Ruth M Cantrill, Debra K Creedy. Effective suckling in relation to naked maternal-infant body contact in the first hour of life: an observation study.BMC Pregnancy Childbirth. 2014; 14: 20.

\section{How to cite this article?}

Tiwari V, Singh N, Purohit A, Shyam S. Role of breast crawl in maternal health and wellbeing. Int J Med Res Rev 2015;3(6):540-546. doi: 10.17511/ijmrr.2015.i6.103. 